\title{
Studi Mengenai Perancangan Campuran Beton Abu Terbang dengan Pendekatan Blended Sand
}

\author{
REZA FAUZI NIRWAN, PRIYANTO SAELAN \\ Jurusan Teknik Sipil, Institut teknologi Nasional, Bandung \\ Email: rezafnirwan@gmail.com
}

\begin{abstract}
ABSTRAK
Penelitian ini dilakukan untuk mengetahui hasil perancangan campuran beton abu terbang yang mensubtitusi semen dengan cara pendekatan sand blended, yaitu abu terbang yang mensubtitusi semen diperlakukan sebagai agregat halus, sehingga agregat halus merupakan campuran dari pasir dan abu terbang. Penelitian dilakukan dengan kuat tekan rencana 20 MPa dan 30 MPa. Substitusi semen oleh abu terbang sebesar $10 \%, 20 \%$, dan $30 \%$ dari berat semen. Ukuran maksimum agregat kasar yang digunakan adalah $20 \mathrm{~mm}$, dan pasir dengan modulus kehalusan 2,768, slump rencana $6 \mathrm{~cm}$ dan $10 \mathrm{~cm}$. Hasil pengujian tekan silinder beton berdiameter $10 \mathrm{~cm}$ dan tinggi $20 \mathrm{~cm}$ menunjukkan bahwa kuat tekan beton abu terbang yang dihasilkan berdekatan dengan beton acuan yaitu beton tanpa abu terbang, untuk semua kadar abu terbang yaitu sampai dengan kadar subtitusi semen oleh abu terbang sebesar $30 \%$. Pendekatan sand blended dapat dilakukan dalam perancangan campuran beton abu terbang.
\end{abstract}

Kata Kunci : beton abu terbang, kuat tekan, pasir blended

\begin{abstract}
This is research was performed to know the result of the test of fly ash concrete mix designed by sand blended method. Fly ash will be treated as fine aggregate so that the total fine aggregate is the consist of fly ash and sand. $20 \mathrm{MPa}$ and 30 MPa concrete mix are designed for $10 \%, 20 \%$ and $30 \%$ by weight of cement subtitution by fly ash. Concrete mix use $20 \mathrm{~mm}$ maximum aggregate size, finess modulus of sand 2.768, and $6 \mathrm{~cm}$ and $10 \mathrm{~cm}$ slump. Compressive strength tests of $10 \mathrm{~cm}$ diameter and $20 \mathrm{~cm}$ height cylinder showed that the stength of fly ash concrete is the same as the strength of initial concrete. Fly ash concrete mix can be designed by sand blended approximation.
\end{abstract}

Keywords : fly ash concrete, compressive strength, blended sand 


\section{Pendahuluan}

Semen merupakan material yang tidak ramah lingkungan, sehingga upaya yang dilakukan untuk mengurangi pencemaran yang diakibatkan oleh beton adalah dengan cara mengurangi kadar semen yang digunakan, dan diganti dengan bahan tambahan lainnya yang mempunyai kemiripan dengan semen. Bahan tambahan pengganti yang sering digunakan adalah abu terbang. Kemiripan sifat ini dapat ditinjau dari dua sifat utama, yaitu sifat fisik dan kimiawi. Secara fisik, material abu terbang memiliki kemiripan dengan semen dalam hal kehalusan butir-butirnya, yaitu lolos ayakan No. 325 (45 mili micron) 5-27\% dengan specific gravity antara $2,15-2,6$. Sifat kimia yang dimiliki oleh abu terbang berupa silica dan alumina dengan presentase mencapai $80 \%$. mensubtitusi langsung sebagian semen dengan abu terbang, dan diikuti dengan pengurangan pasir atau agregat kasar agar volumenya tetap $1 \mathrm{~m}^{3}$ mengakibatkan kuat tekan 28 hari beton menjadi lebih kecil dibandingkan dengan campuran beton menggunakan semen biasa. Jika dikaji dan dianalisis menggunakan formulasi Dreux Gorrisse dengan pendekatan blended sand, perancangan campuran beton abu terbang diduga dapat dilakukan dengan hasil yang lebih baik.

\section{TINJAUAN PUSTAKA}

\subsection{Abu Terbang}

Abu terbang adalah limbah dari hasil pembakaran batu bara pada tungku pembangkit listrik tenaga uap yang berbentuk halus, bundar dan bersifat pozolanik. Ukuran partikel abu terbang bervariasi mulai dari lebih kecil dari $1 \mu \mathrm{m}$ (micrometer) hingga lebih besar dari $100 \mu \mathrm{m}$. Abu terbang yang dapat digunakan untuk campuran pengganti sebagian semen dalam beton diatur dalam ACI Manual of Concrete Practice 1993 Part 1 226.3R-3 dan ASTM C 618, dan dibagi menjadi 3 kelas, yaitu kelas $\mathrm{F}$, kelas $\mathrm{C}$, dan kelas $\mathrm{N}$.

\subsection{Penelitian Mengenai Perancangan Campuran Beton Abu Terbang}

Para peneliti dari berbagai negara telah melakukan berbagai macam penelitian mengenai perancangan campuran beton dengan memanfaatkan abu terbang sebagai bahan subtitusi semen. Patil, et. al (2017) dari India melakukan penelitian mengenai perancangan campuran beton abu terbang untuk mengetahui perbedaan antara kekuatan dan kelecakan dari beton abu terbang dan beton tanpa abu terbang. Jumlah material yang digunakan dalam campuran beton abu terbang ditunjukkan pada Tabel 1.

Tabel 1. Jumlah Material yang Digunakan dalam Campuran Beton Abu Terbang

\begin{tabular}{ccc}
\hline Material & $\begin{array}{c}\text { Weight } \\
{\left[\mathrm{kg} / \mathbf{m}^{3}\right]}\end{array}$ & $\begin{array}{c}\text { Volume } \\
{\left[\mathbf{m}^{3}\right]}\end{array}$ \\
\hline Total bahan cementitious & 476 & - \\
\hline Semen & 333 & 0,1057 \\
\hline Abu terbang & 143 & 0,0636 \\
\hline Air & 142,5 & 0,1425 \\
\hline Bahan tambah & 4,76 & 0,0045 \\
\hline Udara [1\%] & - & 0,01 \\
\hline Total & - & 0,3263 \\
\hline Agregat kasar & 1062 & 0,4085 \\
\hline Agregat halus & 690 & 0,2652 \\
\hline Total & 2375 & 1 \\
\hline (Sumber: Patil, J, & &
\end{tabular}

(Sumber: Patil, J. V, 2017)

Dapat diketahui bahwa untuk beton abu terbang material pengganti semen lebih besar dan kandungan semen lebih kecil. jumlah agregat halus dikurangi tapi jumlah agregat kasar dibuat sama. Jumlah air dan kerapatan berkurang karena kerapatan abu terbang lebih rendah dari 
pada semen. Penelitian telah dilakukan oleh Awanti, et. al (2016) dari India untuk mengetahui proporsi campuran beton abu terbang bervolume tinggi dengan hasil uji kuat tekan beton abu terbang ditunjukkan pada Tabel $\mathbf{2}$.

Tabel 2. Hasil Uji Kuat Tekan Beton Abu Terbang

\begin{tabular}{cc}
\hline $\begin{array}{c}\text { Rancangan } \\
\text { Campuran }\end{array}$ & $\begin{array}{c}\text { Kuat Tekan Kubus Beton Setelah 28 hari } \\
{[\mathrm{MPa}]}\end{array}$ \\
\hline P.35 & 56,1 \\
\hline $50 \mathrm{~F} .35$ & 42,44 \\
\hline $55 F .35$ & 40,62 \\
\hline $60 \mathrm{~F} .35$ & 35,17 \\
\hline $65 F .35$ & 24,42 \\
\hline P.30 & 62,28 \\
\hline $50 F .35$ & 52,1 \\
\hline $55 F .35$ & 47,31 \\
\hline $60 F .35$ & 40,84 \\
\hline $65 F .35$ & 27,69 \\
\hline
\end{tabular}

(Sumber: Awanti, et. al, 2016)

Dari penelitian tersebut diketahui abu terbang lebih efektif pada rasio $w / c$ yang lebih rendah. Selanjutnya penelitian dilakukan oleh Novena, A. (2017) dari Itenas. Komposisi campuran beton abu terbang dihitung dengan cara Dreux, cara penyesuaian volume pasir, dan cara penyesuaian volume batu pecah, dimana semen dimodelkan sebagai semen blended. Komposisi campuran beton abu terbang dengan cara Dreux, ditunjukkan pada Tabel 3.

Tabel 3. Komposisi Campuran Beton Abu Terbang dengan Cara Dreux

\begin{tabular}{|c|c|c|c|c|c|c|}
\hline \multirow{2}{*}{ Bahan } & \multirow{2}{*}{$\begin{array}{c}\text { Campuran Acuan } \\
\text { SNI }\end{array}$} & \multicolumn{5}{|c|}{ Campuran dengan Cara Dreux } \\
\hline & & 1 & 2 & 3 & 4 & 5 \\
\hline Semen $(C 42,5)[\mathrm{kg}]$ & 366,071 & 329,464 & 292,857 & 256,25 & 219,643 & 183,036 \\
\hline Abu terbang [kg] & 0 & 36,6071 & 73,2142 & 109,821 & 146,428 & 183,036 \\
\hline Pasir [kg] & 642,612 & 723,141 & 766,54 & 793,103 & 653,38 & 653,38 \\
\hline Batu pecah [kg] & $1.048,47$ & 954,055 & 896,042 & 855,742 & 987,295 & 974,27 \\
\hline Air $[\mathrm{kg}]$ & 205 & 205 & 205 & 205 & 205 & 205 \\
\hline Kuat tekan semen & 42,5 & 39,074 & 36,154 & 33,5 & 31,494 & 28,871 \\
\hline \multicolumn{7}{|l|}{28 Hari [MPa] } \\
\hline Volume & 1 & 1 & 1 & 1 & 1 & 1 \\
\hline Slump [cm] & 5 & 8 & 7 & 7 & 9 & 16 \\
\hline $\begin{array}{c}f_{c}^{\prime} \text { prediksi rata - rata } \\
{[\mathrm{MPa}]}\end{array}$ & 20,9 & 21,68 & 25,52 & 20,39 & 26,32 & 24,13 \\
\hline$f_{c}^{\prime}$ rata-rata $[\mathrm{MPa}]$ & 20,79 & 20,25 & 22,06 & 17,01 & 10,8 & 6,83 \\
\hline
\end{tabular}

(Sumber: Novena, A., 2017)

Perancangan campuran beton abu terbang dengan pendekatan blended cement dimana kuat tekan beton yang dihasilkan berdekatan dengan kuat tekan beton tanpa abu terbang, hanya dapat dilakukan sampai dengan kadar subtitusi semen oleh abu terbang maksimal $20 \%$ dari berat semen. 


\subsection{Perancangan Campuran Beton Abu Terbang Dengan Pendekatan Blended Sand}

Pencampuran beton dengan pendekatan blended sand dapat dilakukan menggunakan formulasi Dreux Gorrisse, dimana abu terbang yang mensubtitusi semen diperlakukan sebagai agregat halus. Rumus faktor granular $G$ pada perancangan dengan cara Dreux menjadi:

$$
G=K * \text { Volume (pasir }+ \text { abu terbang) }
$$

Nilai $K$ dapat diperlihatkan pada Tabel 4.

Tabel 4. Nilai $K$ untuk $0,4 \leq G \leq 0,6$

\begin{tabular}{ccc}
\hline No. & $\boldsymbol{V}($ pasir + abu terbang $) / V$ total agregat & $\boldsymbol{K}$ \\
\hline 1 & $\leq 0,26$ & 3 \\
\hline 2 & $0,26-0,29$ & 2 \\
\hline 3 & $0,29-0,39$ & 1,8 \\
\hline 4 & $0,39-0,43$ & 1,5 \\
\hline 5 & $0,43-0,49$ & 1,8 \\
\hline 6 & $\geq 0,50$ & 1,5 \\
\hline
\end{tabular}

(Sumber: Thesia, Z., 2013)

Kuat tekan beton abu terbang dapat dihitung dengan menggunakan rumus Dreux:

$$
f_{c}=G * f_{p c} *\left(\frac{c}{w}-0,5\right)
$$

halmana:

$f_{c} \quad=$ kuat tekan silinder beton berdiameter $150 \mathrm{~mm}$ dan tinggi $300 \mathrm{~mm}$ pada umur 28 hari [MPa],

$f_{p c} \quad=$ kekuatan tekan mortar semen umur 28 hari [MPa],

$G \quad=$ faktor granular atau faktor kekompakan butiran,

$c / w \quad=$ rasio berat semen terhadap berat air.

\section{METODE PENELITIAN}

\subsection{Prosedur Penelitian}

Prosedur penelitian dilakukan dengan metoda tertera pada Gambar 1. 
Studi Mengenai Perancangan Campuran Beton Abu Terbang dengan Pendekatan Blended Sand

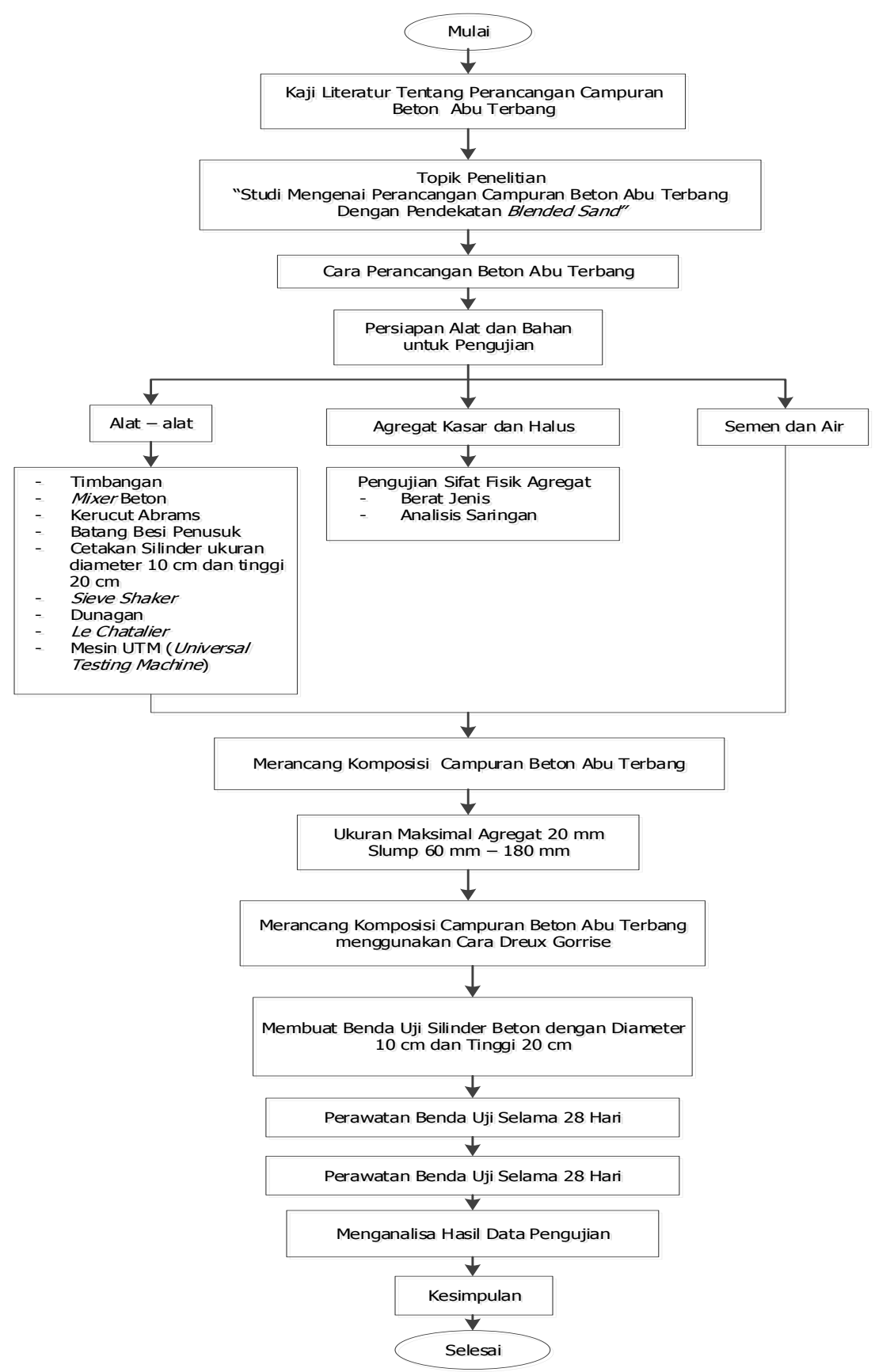

Gambar 1. Bagan alir metode penelitian

\subsection{Data Penelitian}

Data primer yang digunakan adalah data material pada Tabel 5.

Tabel 5. Hasil Pengujian Fisik Material yang Digunakan

\begin{tabular}{ccccc}
\hline Parameter & Semen (C42) & Abu Terbang & Agregat Kasar & Agregat Halus \\
\hline Berat jenis kondisi SSD $\left[\mathrm{kg} / \mathrm{m}^{3}\right]$ & 3.150 & 2.680 & 2.605 & 2.546 \\
\hline Berat jenis kondisi kering $\left[\mathrm{kg} / \mathrm{m}^{3}\right]$ & - & - & 2.461 & 2.434 \\
\hline Modulus Kehalusan (FM) & - & - & - & 2,768 \\
\hline
\end{tabular}




\subsection{Variabel Penelitian}

Variabel dari penelitian ini terdiri dari:
(1) kuat tekan 28 hari beton (20 MPa dan $30 \mathrm{MPa}$ );
(2) slump rencana $(6 \mathrm{~cm}$ dan $10 \mathrm{~cm})$;
(3) persen subtitusi semen oleh abu terbang (0\%, $10 \%$, $20 \%$, dan $30 \%)$.

\subsection{Analisis Data}

Analisis data dilakukan dengan cara membuat grafik yang menggambarkan:

(1) hubungan antara persentase abu terbang dalam komposisi campuran beton dengan kuat tekan 28 hari beton;

(2) hubungan antara sebaran kuat tekan rata-rata aktual disekitar kuat tekan prediksi untuk setiap persentase abu terbang dalam campuran beton.

\section{HASIL PENELITIAN DAN PEMBAHASAN}

\subsection{Hasil Penelitian}

Hasil kuat tekan pada umur 28 hari ditunjukan pada Tabel 6, Tabel 7, Tabel 8, dan Tabel 9.

Tabel 6. Hasil Uji Tekan Campuran Beton dengan Cara Dreux untuk Kuat Tekan 20 MPa dengan S/ump 6 cm

\begin{tabular}{|c|c|c|c|c|}
\hline \multirow[b]{2}{*}{ Bahan } & \multicolumn{4}{|c|}{ Campuran Beton } \\
\hline & $\begin{array}{c}1 \\
(0 \% \text { FA) }\end{array}$ & $\begin{array}{c}2 \\
(10 \% \mathrm{FA})\end{array}$ & $\begin{array}{c}3 \\
(20 \% \text { FA) }\end{array}$ & $\begin{array}{c}4 \\
\text { (30\% FA) }\end{array}$ \\
\hline Semen $(C 42,5)[\mathrm{kg}]$ & 312,5 & 281,25 & 250 & 218,75 \\
\hline Abu terbang $[\mathrm{kg}]$ & 0 & 31,25 & 62,5 & 93,75 \\
\hline Pasir $[\mathrm{kg}]$ & 664,506 & 751,07 & $1.074,412$ & $1.359,564$ \\
\hline Batu pecah $[\mathrm{kg}]$ & $1.070,655$ & 979,48 & 638,225 & 346,465 \\
\hline Air $[\mathrm{kg}]$ & 208,194 & 208,194 & 208,194 & 208,194 \\
\hline Tambahan & 34,703 & 34,611 & 68,447 & 68,241 \\
\hline Slump aktual $[\mathrm{cm}]$ & 4 & 8,5 & 5 & 1 \\
\hline Umur pengujian [hari] & 19 & 14 & 14 & 14 \\
\hline Korelasi umur pengujian [\%] & 94,011 & 88 & 88 & 88 \\
\hline$f_{c}^{\prime}$ rata - rata pengujian $[\mathrm{MPa}]$ & 13,542 & 9,645 & 10,128 & 10,487 \\
\hline$f_{c}^{\prime}$ hari dari umur pengujian [MPa] & 14,404 & 10,960 & 11,509 & 11,917 \\
\hline$f_{c}^{\prime}$ rata - rata prediksi 28 hari $[\mathrm{MPa}]$ & 15,704 & 12,884 & 11,447 & 10,567 \\
\hline
\end{tabular}


Studi Mengenai Perancangan Campuran Beton Abu Terbang dengan Pendekatan Blended Sand

Tabel 7. Hasil Uji Tekan Campuran Beton dengan Cara Dreux untuk Kuat Tekan 20 MPa dengan S/ump $10 \mathrm{~cm}$

\begin{tabular}{|c|c|c|c|c|}
\hline \multirow[b]{2}{*}{ Bahan } & \multicolumn{4}{|c|}{ Campuran Beton } \\
\hline & $\begin{array}{c}1 \\
(0 \% \text { FA })\end{array}$ & $\begin{array}{c}2 \\
(10 \% \text { FA })\end{array}$ & $\begin{array}{c}3 \\
(20 \% \text { FA) }\end{array}$ & $\begin{array}{c}4 \\
(30 \% \text { FA) }\end{array}$ \\
\hline Semen $(C 42,5)[\mathrm{kg}]$ & 325 & 292,5 & 260 & 227,5 \\
\hline Abu terbang $[\mathrm{kg}]$ & 0 & 32,5 & 65 & 97,5 \\
\hline Pasir $[\mathrm{kg}]$ & 664,506 & 751,07 & $1.076,958$ & $1.357,018$ \\
\hline Batu pecah [kg] & $1.040,176$ & 948,22 & 609,57 & 263,886 \\
\hline Semula & 216,522 & 216,522 & 216,522 & 216,522 \\
\hline Tambahan & 34,094 & 33,986 & 33,731 & 32,418 \\
\hline Slump aktual $[\mathrm{cm}]$ & 13 & 12,5 & 5 & 7,5 \\
\hline Umur pengujian [hari] & 14 & 20 & 20 & 19 \\
\hline Korelasi umur pengujian [\%] & 88 & 94,702 & 94,702 & 94,011 \\
\hline$f_{c}^{\prime}$ rata - rata pengujian $[\mathrm{MPa}]$ & 11,883 & 11,513 & 12,191 & 12,866 \\
\hline$f_{c}^{\prime} 28$ hari dari umur pengujian [MPa] & 13,503 & 12,157 & 12,873 & 13,686 \\
\hline$f_{c}^{\prime}$ rata - rata prediksi 28 hari $[\mathrm{MPa}]$ & 13,257 & 13,066 & 13,358 & 15,066 \\
\hline
\end{tabular}

Tabel 8. Hasil Uji Tekan Campuran Beton dengan Cara Dreux untuk Kuat Tekan 30 MPa dengan Slump 6 cm

\begin{tabular}{|c|c|c|c|c|c|}
\hline \multirow{3}{*}{\multicolumn{2}{|c|}{ Bahan }} & \multicolumn{4}{|c|}{ Campuran Beton } \\
\hline & & 1 & 2 & 3 & 4 \\
\hline & & ( $0 \%$ FA) & (10 \% FA) & (20\% FA) & (30 \% FA) \\
\hline \multicolumn{2}{|c|}{ Semen $(C 42,5)[\mathrm{kg}]$} & 412,5 & 371,25 & 330 & 288,75 \\
\hline \multicolumn{2}{|c|}{ Abu terbang $[\mathrm{kg}]$} & 0 & 41,25 & 82,5 & 123,75 \\
\hline \multicolumn{2}{|r|}{ Pasir $[\mathrm{kg}]$} & 664,506 & 730,702 & $1.010,762$ & $1.214,442$ \\
\hline \multicolumn{2}{|c|}{ Batu pecah [kg] } & 995,11 & 922,17 & 627,805 & 414,195 \\
\hline \multirow{2}{*}{ Air $[\mathrm{kg}]$} & Semula & 206,25 & 206,25 & 206,25 & 206,25 \\
\hline & Tambahan & 33,192 & 33,057 & 32,771 & 32,573 \\
\hline \multicolumn{2}{|c|}{ Slump aktual $[\mathrm{cm}]$} & 10 & 9 & 4 & 1 \\
\hline \multicolumn{2}{|c|}{ Umur pengujian [hari] } & 18 & 18 & 18 & 12 \\
\hline \multicolumn{2}{|c|}{ Korelasi umur pengujian [\%] } & 93,199 & 93,199 & 93,199 & 83,599 \\
\hline \multicolumn{2}{|c|}{$f_{c}^{\prime}$ rata - rata pengujian $[\mathrm{MPa}]$} & 19,099 & 23,452 & 22,769 & 20,053 \\
\hline \multicolumn{2}{|c|}{$f_{c}^{\prime} 28$ hari dari umur pengujian [MPa] } & 20,493 & 24,946 & 24,430 & 23,987 \\
\hline \multicolumn{2}{|c|}{$f_{c}^{\prime}$ rata - rata prediksi 28 hari [MPa] } & 20,345 & 24,289 & 24,028 & 23,641 \\
\hline
\end{tabular}


Tabel 9. Hasil Uji Tekan Campuran Beton dengan Cara Dreux untuk Kuat Tekan 30 MPa dengan S/ump $10 \mathrm{~cm}$

\begin{tabular}{|c|c|c|c|c|c|}
\hline \multirow{3}{*}{\multicolumn{2}{|c|}{ Bahan }} & \multicolumn{4}{|c|}{ Campuran Beton } \\
\hline & & 1 & 2 & 3 & 4 \\
\hline & & ( $0 \%$ FA) & $(10 \%$ FA) & $(20 \%$ FA) & (30 \% FA) \\
\hline \multicolumn{2}{|c|}{ Semen $(C 42,5)[\mathrm{kg}]$} & 437,5 & 393,75 & 350 & 306,25 \\
\hline \multicolumn{2}{|c|}{ Abu terbang $[\mathrm{kg}]$} & 0 & 43,75 & 87,5 & 131,25 \\
\hline \multicolumn{2}{|r|}{ Pasir [kg] } & 796,9 & 766,346 & $1.005,67$ & $1.206,804$ \\
\hline \multicolumn{2}{|c|}{ Batu pecah $[\mathrm{kg}]$} & 804,95 & 874,238 & 578,31 & 367,305 \\
\hline \multirow{2}{*}{ Air $[\mathrm{kg}]$} & Semula & 218,75 & 218,75 & 218,75 & 218,75 \\
\hline & Tambahan & 32,037 & 32,817 & 31,680 & 31,482 \\
\hline \multicolumn{2}{|c|}{ Slump aktual $[\mathrm{cm}]$} & 7 & 12 & 5,5 & 4 \\
\hline \multicolumn{2}{|c|}{ Umur pengujian [hari] } & 11 & 11 & 10 & 10 \\
\hline \multicolumn{2}{|c|}{ Korelasi umur pengujian [\%] } & 80,847 & 80,847 & 77,662 & 77,662 \\
\hline \multicolumn{2}{|c|}{$f_{c}^{\prime}$ rata - rata pegujian $[\mathrm{MPa}]$} & 22,573 & 23,623 & 22,952 & 22,132 \\
\hline \multicolumn{2}{|c|}{$f_{c}^{\prime} 28$ hari dari umur pengujian [MPa] } & 27,921 & 29,219 & 29,553 & 28,497 \\
\hline \multicolumn{2}{|c|}{$f_{c}^{\prime}$ rata - rata prediksi 28 hari $[\mathrm{MPa}]$} & 24,859 & 25,832 & 24,491 & 24,135 \\
\hline
\end{tabular}

Pada Gambar 1, Gambar 2, Gambar 3, dan Gambar 4 menunjukkan hasil uji tekan campuran beton dalam grafik.

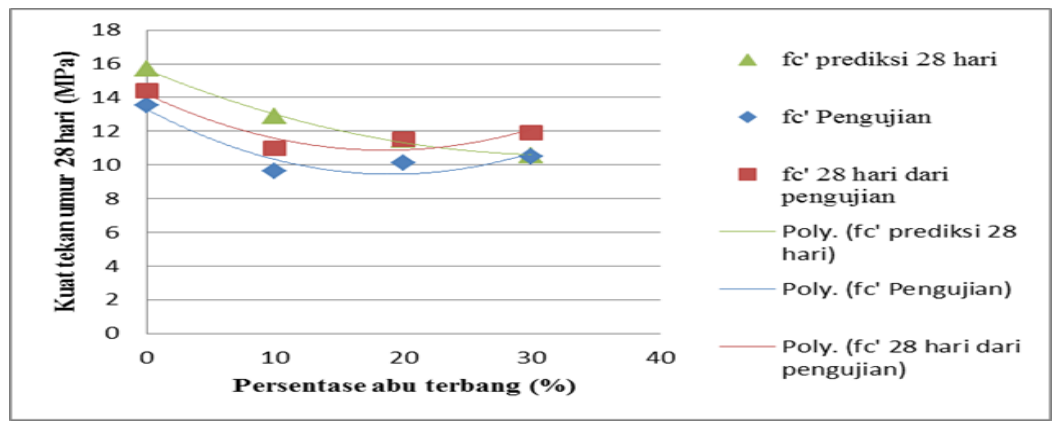

Gambar 1. Hasil uji tekan campuran beton dengan cara Dreux untuk kuat tekan renana 20 MPa dengan s/ump $6 \mathrm{~cm}$

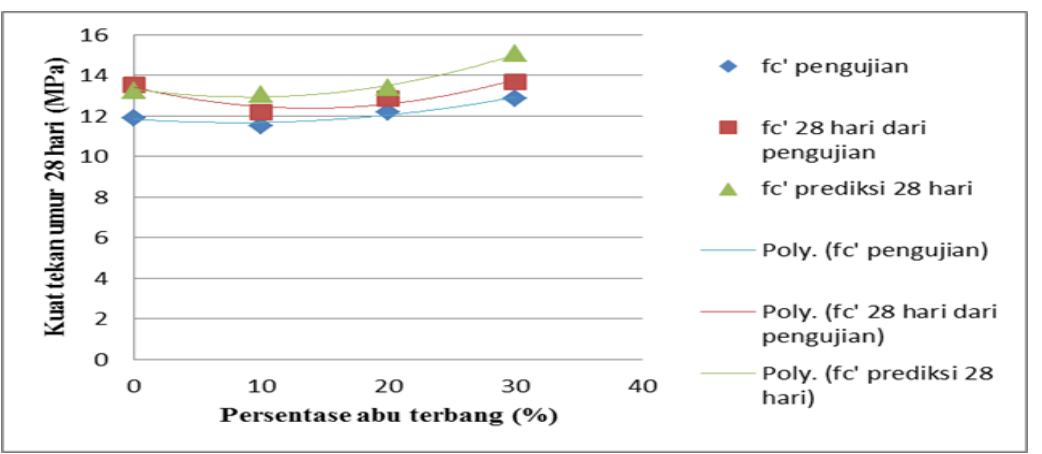

Gambar 2. Hasil uji tekan campuran beton dengan cara Dreux untuk kuat tekan renana $20 \mathrm{MPa}$ dengan s/ump $10 \mathrm{~cm}$ 


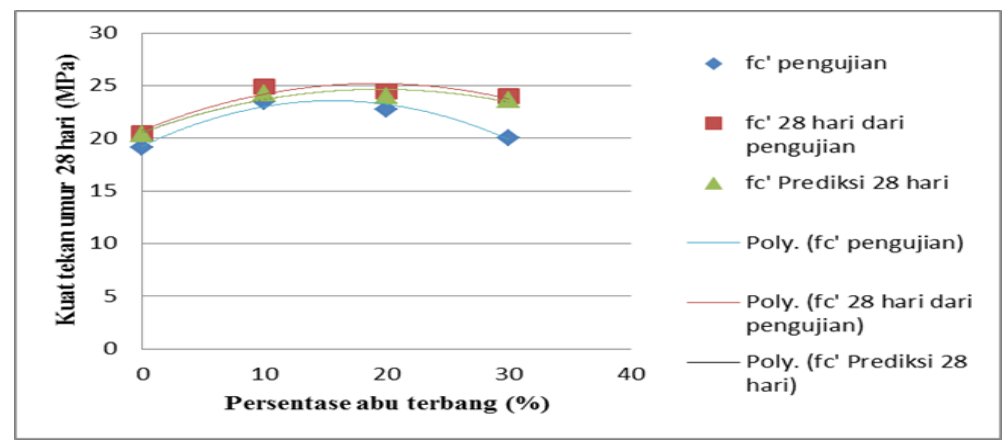

Gambar 3. Hasil uji tekan campuran beton dengan cara Dreux untuk kuat tekan renana $30 \mathrm{MPa}$ dengan s/ump $6 \mathrm{~cm}$

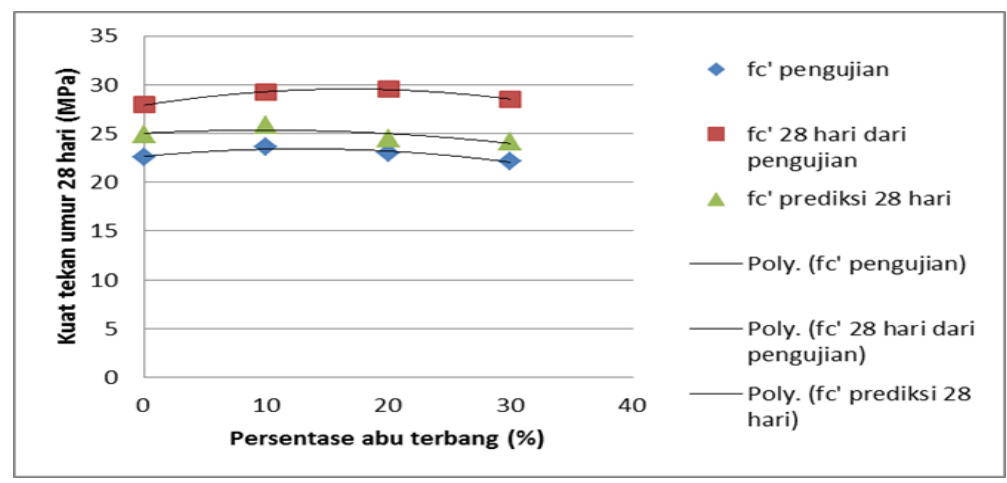

\section{Gambar 4. Hasil uji tekan campuran beton dengan cara Dreux untuk kuat tekan renana $30 \mathrm{MPa}$ dengan s/ump $10 \mathrm{~cm}$}

\subsection{Pembahasan Hasil Penelitian}

1. Kuat tekan pengujian berdekatan dengan kuat tekan prediksi. Hal ini menunjukkan bahwa pemodelan blended sand dalam beton abu terbang dapat diaplikasikan dalam perancangan beton abu terbang.

2. Kuat tekan beton abu terbang yang dihasilkan berdekatan dengan beton acuan yaitu beton tanpa abu terbang, untuk semua kadar abu terbang yaitu sampai dengan kadar subtitusi semen oleh abu terbang sebesar $30 \%$. Dibandingkan dengan cara blended cement yang menghasilkan kuat tekan beton abu terbang yang berdekatan dengan kuat tekan beton tanpa abu terbang yang hanya sampai pada kadar subtitusi semen sebesar $20 \%$, maka hasil perancangan beton abu terbang dengan cara bended sand menghasilkan kuat tekan beton abu terbang yang lebih berdekatan dengan kuat tekan beton tanpa abu terbang.

\section{KESIMPULAN}

\subsection{Kesimpulan}

Berdasarkan hasil pengujian dan pembahasan dapat disimpulkan:

(1) kuat perancangan campuran beton abu terbang dengan pendekatan blended sand dapat diaplikasikan untuk merancang campuran beton abu terbang;

(2) hasil perancangan campuran beton abu terbang dengan pendekatan blended sand lebih baik dari perancangan campuran beton abu terbang dengan pendekatan blended cement;

(3) perancangan campuran beton abu terbang dengan pendekatan blended sand dapat diaplikasikan sampai dengan kadar subtitusi semen oleh abu terbang sebesar $30 \%$ dari berat semen.

\subsection{Saran}


Saran untuk penelitian perancangan campuran beton abu terbang dengan pendekatan blended sand adalah perlu dilakukan penelitian lebih lanjut dengan kadar subtitusi semen oleh abu terbang lebih besar dari $30 \%$ berat semen.

\section{DAFTAR RUJUKAN}

Awanti, S. S. (2016). Mix Design Curves for High Volume Fly Ash Concrete. World Academy of Science, Engineering and Technology International Journal of Civil and Environmental engineering, 10(10), 1310-1315.

Novena, A. (2017). Studi Mengenai Perancangan Campuran Beton Abu Terbang Dengan Pendekatan Blended Cement. Tugas Akhir. Bandung: Jurusan Teknik Sipil Institut Teknologi Nasional - Bandung.

Patil, J. V. (2017). Partial Replacement of Cement by Fly Ash in Concrete Mix Design. International Research Journal of Engineering and Technology (IRJET), 4(11), 11481150.

Thesia, Z. (2013). Studi Mengenai Perancangan Campuaran Beton Cara Dreux Gorrise. Tugas Akhir. Bandung: Jurusan Teknik Sipil Institut Teknologi Nasional - Bandung. 